\title{
L'ARPA I LA CÍTARA: LA RELACIÓ ENTRE VERDAGUER I PEDRELL
}

\author{
Francesc BONASTRE \\ Universitat Autònoma de Barcelona
}

\begin{abstract}
Al Prof. Dr. Josep Pavia i Simó, musicus et cantor i excel-lent company, en la seva segona iubilatio.
\end{abstract}

\begin{abstract}
Felip Pedrell and Jacint Verdaquer were the most important figures in the musical and poetical landscape in Catalunya during the latter third of the XIX century. The process of rediscovering their own voices is an integral part of their work. In this article we have published the fundamental facts that go to reveal their own mutual awareness of each other and of what their work had in common.
\end{abstract}

\section{Resum}

Felip Pedrell i Jacint Verdaguer són les figures més importants de la música i de la poesia, respectivament, a la Catalunya del darrer terç del segle XIX; el procés de retrobament de la veu pròpia forma part del nucli conceptual de la seva obra. En aquest article es donen a conèixer les dades fonamentals que palesen tant el seu mutu coneixement personal com la comuna relació entre les seves obres.

Aquest any celebrem el centenari de la mort de Verdaguer, el poeta de Catalunya per antonomàsia. És de tothom conegut l'impacte que la poesia verdagueriana tingué a la Catalunya del darrer quart del segle XIX, i, tanmateix, l'extraordinària acollida que meresqué per part dels compositors, que segons les dades de Mn. Francesc Baldelló, aplegades en un treball de recol·lecció que malauradament es perdé durant la guerra civil de 1936-39, haurien arribat a produïr unes 1.200 obres; per això el considerava com el poeta més musicat d'Europa', i també per això he emprat l'adjectiu "extraordinari".

1. Baldelló, Francesc: Mossèn Cinto i la Música. Conferència llegida el dia 31 d’agost del 1952 al "Centre Paroquial de Cultura" de San Feliu de Codines, en sessió commemorativa del Cinquantè Aniversari de la mort de Mossèn Jacint Verdaguer. Barcelona, 1953, p. 63. 
Les raons de l'èxit de la poesia de Mn. Cinto Verdaguer en la societat catalana del seu temps són a bastament conegudes; no en canvi, les del seu atractiu damunt els compositors, que mereixen una primera reflexió atenta.

La poesia de Verdaguer abraça tres temes principals, que troben el seu ressò en la composició musical religiosa, èpica i patriòtica.

El cant religiós a la Catalunya del darrer quart del segle XIX està empeltat dels models italianitzants de caràcter operístic, que envaeixen la pràctica usual tant en la litúrgia llatina com en els cants devocionals en la llengua vernacla ${ }^{2}$. També hi ha, evidentment, una música de caire popular, lligada tant a la tradició històrica -per exemple, els Goigs-com a la factura o a l'ús que se'n feia en els actes devocionals, no lligats necessàriament a la litúrgia ni als ritus sacramentals: els rosaris, els trisagis, les novenes, els tríduums; els cants del mes de maig, dedicat a la Mare de Déu; els del mes de juny, dedicat al Sagrat Cor de Jesús; les nadales, els cants catequístics, etc.

Els corrents cecilianistes europeus anaren imposant uns altres models a la música religiosa, deslligats de l'evolució natural de la societat, que consideraven allunyats de l'esperit religiós per causa de la influència dels models operístics italianitzants. L'interès per l'antiga polifonia imitativa, sorgida al caliu de la "resurrecció" de Palestrina ${ }^{3}$ i el cant gregorià com a símbol de la fidelitat a les fonts històriques cristianes, com també a la unitat i la bonesa ontològica i estètica, tindrien la seva eclosió en el Motu Proprio de Pius X de 1903, publicat un any després de la mort de Verdaguer.

Al marge o no d'aquest procés estètico-litúrgic, la preocupació per la dignitat i la idoneïtat del cant en llengua vernacla ${ }^{4}$ continuà a Catalunya el seu camí natural, que trobà en la poesia de Verdaguer un element dinamitzador.

Tot i que el copiosíssim epistolari de Verdaguer i de Pedrell no palesen, pel que fa als documents coneguts avui dia, cap relació documental entre ells, posseïm en canvi un altre tipus de proves històriques que demostren almenys, la certesa de llur pròpia coneixença.

El primer d'octubre de 1880 es publicaven a Tarragona les bases del "Nacional Homenaje de las Ciencias, Letras y Artes Españolas al Sacratísimo Corazón de Jesús”, que s'havia de celebrar els dies 26 i 27 de juny de $1881 .{ }^{5}$ El certamen comprenia diverses manifestacions, entre les quals hi havia dos premis per a l'apartat de la composició musical:

2. Pedrell, F.: Jornadas de Arte. París, Ollendorf, 1911. En el capítol titulat Un magisterio in partibus infidelium explica la situació d'incúria musical a la col-legiata de Santa Anna de Barcelona, d'on fou nomenat mestre de capella i dimití l'any 1883. Cf. ibid., p. 181-192.

3. El testimoni més antic fou la cèlebre biografia de BAINI, G.: Memorie Storiche-Chritiche della vita e delle opere di Giovanni Pierluigi Palestrina. Roma, 1828, 2 vols.

4. El Motu Proprio de Pius X consagra un apartat al cant en llengua vernacla, que estableix el seu dret a existir i els seus models a seguir.

5. Nacional Homenaje de las Ciencias, Letras y Artes Españolas al Sacratísimo Corazón de Jesís. del qual se’n feren dues edicions: la primera, més breu, editada a Tarragona, Imp. Puigrubí i Arís, 26 de juny de 1881, i la segona, amb 
“19. Las señoras Celadoras del Apostolado de la Oración de Tarragona ofrecen una «Lira de oro y plata» á la mejor Composición musical de carácter clásico religioso, á cuarteto vocal con acompañamiento de cuerda y armonium, del Himno de Laudes del Oficio del Sagrado Corazón de Jesús, que empieza:

\section{Summi Parentis Filio}

Patri Futuri sceculi...

20. Dos sacerdotes devotos del Sagrado Corazón de Jesús ofrecen un «Laúd de plata» á la mejor Composición musical de género popular, aplicable á la conocida poesía de mossén Verdaguer, «Jesús als pecadors», que empieza «Mirau mon Cor de Pare amorosíssim» y se halla en la colección de este autor, «Idilis y Cants Místichs».

El canto deberá ser variado por lo menos en tres estrofas, que podrán ser á solo, duo, trío ó coro, á elección del autor.

Deberá añadirse un sencillo acompañamiento o armonzación para instrumentos de teclado". ${ }^{6}$

En el jurat, que presidia el canonge Joan Baptista Grau i Espinós, Vicari general de l'Arxidiòcesi, hi havia figures molt importants de la cultura catalana i hispánica del moment: hi destaquen especialment Fèlix Sardà i Salvany, el jesuïta Fidel Fita, els catedràtics de Literatura Marcelino Menéndez y Pelayo ${ }^{7}$, Manuel Milà i Fontanals i Joaquim Rubió i Ors; quant a la música, la responsabilitat recaigué damunt Rafael Maneja i Ribera, mestre de capella de la catedral; Ramon Bonet i Vallverdú, organista de l'esmentat centre, i un anomenat "José" Pedrell, "profesor de música y compositor", que és en realitat Felip Pedrell. ${ }^{8}$

\section{Jesús als Pecadors, l'encís d'un poètica singular}

El certamen de Tarragona corrobora, pel que acabem d'esmentar, una primera constatació de la relació Verdaguer-Pedrell, pel fet d'estar aquest darrer formant part del jurat en el qual es premiava, segons les bases, una composició musical sobre la poesia de Verdaguer Jesús als peca-

tots els treballs publicats, a Barcelona, Imprenta y Librería Religiosa y Científica del heredero de D. Pablo Riera, 1882. La convocatòria dels dos premis citats es troba a la pàgina 6 de l'edició de 1881 , i a la pàgina 7 de la de 1882 . Des d'ara seguim l'edició de 1882, per ser més completa que la de Tarragona de l'any anterior.

Quant als textos catalans i castellans citats en aquest treball, servem sempre la grafia original.

6. Ibid., id., nota 4, especifica la identitat de dits sacerdots: “(4) Dr. Tomás Sucona y Dr. José Vinyas, Canónigos del Sacro-Monte de Granada".

7. "Para el certámen del Sagrado Corazón de Jesús que tendrá lugar el próximo mes de junio en esta capital ha sido invitado el tan renombrado jóven y célebre historiador Sr. Menendez Pelayo, el cual ha contestado á la atenta invitacion que se le dirigió, prometiendo asistir á dicho acto". Diario de Tarragona, 13 d'abril de 1881, p. 2, col. c. L'esmentat diari havia publicat una biografia laudatòria de Menéndez i Pelayo els dies 8, 9 i 10 d'abril de 1881, signada per "un montañés".

8. Ibid., p. 18 i 15, respectivament. El Diario de Tarragona del 28 d'abril de 1881 dóna a conèixer els noms d'alguns membres del jurat, entre els quals esmenta en estil indirecte ("se dice que que formarán parte del jurado hombres tan eminentes como..." a un tal "D. José Pedrell, reputado compositor de música". Ibid., 28 d'abril de 1881, p. 2, col. c. L'edició del dia 1 de maig dóna a conèixer oficialment els membres del jurat, entre els que es troba, amb el nom ja rectificat, "D. Felipe Pedrell". Ibid., 1 de maig de 1881. p. 2, col. c.

La identificació correcta de Felip Pedrell es troba també a l'Epistolari de Jacint Verdaguer, vol. III, a càrrec de J. M. de Casacuberta i J. Torrent Fàbregas. Barcelona, 1971, p. 56, nota 5, corresponent a la carta de Vicari general de Tarragona a Verdaguer (26 de setembre de 1880). 
dors («Mirau mon cor»), a bastament coneguda segons el document, tot i la seva recent publica. ció l'abril del 1879. ${ }^{9}$

Curiosament, aquest mateix text havia estat musicat per Pedrell durant el seu sojorn a París, a principis de 1880, i, en tot cas, abans del 23 de febrer d'aquest any, tal i com ho registra el seu autor. ${ }^{10}$ Fins a quin punt aquesta composició pogué tenir alguna relació amb la tria que se'n feu per al concurs de Tarragona, és difícil de poder-ho considerar, per tal com el premi fou ofert per dos canonges de Granada ${ }^{11}$; altrament, el caràcter de l'obra pedrelliana s'allunya totalment de les bases de la convocatòria, expressades més amunt: no és popular, ni les estrofes posseeixen més que una sola veu, amb un acompanyament instrumental refinat, i destriat de la simple vocalitat formal; la declamació dramàtica del text verdaguerià es fonamenta més aviat en la puixança d'una música d'intensa emotivitat, molt propera a l'estètica expressiva de l'òpera francesa del moment, que Pedrell coneixia molt bé. ${ }^{12}$

El vincle -si és que n'hi ha algun-potser li vingué de l'atracció interna del poema de Verdaguer, cosa no gens rara si tenim en compte que l'any 1880 constituí per a Pedrell una data certament propícia per a la composició d'obres en llengua catalana ${ }^{13}$ : el cicle de 12 Lieder titulat $L a$ Primavera, sobre poemes de Francesc Matheu ${ }^{14}$; l'Himne a Venus, per a tiple i conjunt instrumental, amb text de Víctor Balaguer; Llevant Déu, per a tenor i quartet de corda, amb text de Careta i Vidal; Cinc Lieder per a cant i piano, amb textos de F. Matheu, V. Balaguer, I. Armengol i Careta Vidal; la recomposició dels quatre darrers Lais de 1879; Sirventès, per a baríton i piano, amb text de V. Balaguer, de la seva tragèdia Lo comte de Foix (després incorporat a Els Pirineus); Balada per a baríton i piano, amb text de G. Rosselló (de l'òpera inacabada Le Roi Léar), i Sis Lieder per a cant i piano, amb text de M. Morera ${ }^{15}$. Aquest conjunt de trenta-una obres en llengua catalana formen un context molt significatiu, del qual emergeix el Lament Jesús als pecadors de Verdaguer.

9. Epistolari... Id. id., p. 37, nota 6, en relació a una recensió de l'obra a càrrec del canonge B. Ribas al Diario de Barcelona el 25 d'abril de 1879, “... quan tot just el llibre havia estat posat a la venda”.

10. Pedrell, F.: Catàleg autògraf de les seves obres. Ms. M 1970 de la BC. Al foli 32 ens diu: “Año 1880 /.../Op. 102 / Jesús als pecadors, Lamento ó Cántico para / Tenor con acompañamiento de cuarteto y Piano, y Armonium ad libitum (Poesía catalana de D. Jacinto Verdaguer)". Un xic més avall, després de l'op. 104, hi trobem l'anotació: "(salida de París 23 de febrero)".

11. Vegeu la nota 6.

12. L'obra es conserva a la Biblioteca de Catalunya. La seva interpretació més recent finals de 2001 al Paraninf de la universitat de Barcelona i a principis de 2002 a la Biblioteca-Museu Víctor Balaguer de Vilanova i La Geltrú fou molt ben rebuda pel públic.

13. Com assenyala el mateix Pedrell, la musicació de textos catalans com a Lieder no era molt habitual a l'època; la referència es troba sovint a les memòries del compositor, que es vegé obligat a fer una defensa del català com a vehicle lingüístic idoni per a l'òpera al seu Por nuestra música (Barcelona, 1891, p. 46-47: “/.../ porque el catalán es musical por admirable manera, musical como ninguna lengua, ni aun la que se ha dado en llamar lengua oficial o natural de la música..."), com també, sovint, a la seva autobiografia.

14. Cf. l'edició crítica a càrrec de F. Bonastre, Diputació de Tarragona, 1991, dins la sèrie «Quaderns de Música Històrica Tarragonina», de l'Institut d'Eatudis Tarraconenses "Ramon Berenguer IV".

15. Bonastre, F.: Felipe Pedrell. Acotaciones a una idea. Tarragona, 1977, p. 147-149. 
A la convocatòria dels 21 premis del Certamen de Tarragona hi optaren 138 candidatures $^{16}$; pel que fa als de música, s'hi presentaren bastants compositors: onze al núm. 19 (Himne de Laudes) i catorze al número 20 (Jesús als pecadors, "Mirau mon cor"). Malauradament, no hem conservat el nom dels concursants que no van guanyar, perquè s'hagueren d'identificar mitjançant lemes, que foren destruïts públicament després de la proclamació oficial dels guanyadors, el 26 de juny de $1881 .^{17}$

El veredicte del jurat sobre la música per al poema verdaguerià Jesús als pecadors atorgà el premi al mestre Joan Carreras i Dagas ${ }^{18}$, que concursà amb el número 126 , essent el seu lema «Cor de Jesús. oh cítara sagrada -que abeura en rius de música en lo cel -sias font de mos càntichs regalada $-\mathrm{y}$ rajaràn més dolsos que la mel $^{19}{ }$, i l'accèsit al número 69 , que amb el lema «Tuus sum ego, salvum me fac» corresponia al mestre Damià Andreu i Sitjes, organista de Santa Maria de Mahó. A la memòria del Secretari, que fou llegida en públic, es féu l'avaluació artística d'ambdues composicions: la de Joan Carreras de plata". ${ }^{20}$

“... es amorosa, popular, reune todas las condiciones del tema y merece el premio del laud

i la de Damià Andreu

“... es otra canción de género popular, bien compuesta y digna del accésit”. ${ }^{21}$

Joan Carreras també es presentà al tema 19 abans esmentat (Himne de Laudes de la festivitat del Sagrat Cor) amb el número 105, i el lema «Ut Deus Domini nostri Jesuchristi [sic], Pater Gloriae det vobis... etc». No s'adjudicà el premi, però sí l'acèssit, que recaigué sobre Carreras. El comentari del jurat, llegit pel secretari, deia el següent:

“... El himno musical que lleva el núm. 105, si no reune todas las condiciones necesarias para alcanzar el premio señalado al tema, las tiene, aunque poco elevado en las modulaciones y sencillo en los acordes, para el accésit que se le asigna". ${ }^{22}$

$$
* * *
$$

16. Nacional Homenaje... Barcelona, 1882, p. 9-14.

17. Ibid., (Relación del acto del Certamen...): "Acto continuo se procedió a quemar las carpetas que contenían los lemas de los trabajos no premiados"., p. 23.

18. Joan Carreras i Dagas (Girona 1835 - Barcelona 1900) es presentava com a "organista de Santa Maria de La Bisbal [de l'Empordà] ".

19. Els versos del tema corresponen a la segona estrofa del primer poema de la mateixa colecció verdagueriana que incloïa el proposat "Jesús als Pecadors": Idilis y cants místichs. Barcelona, 1879, [Cor de Jesús, hort coronat d'espines...].

20. Nacional Homenaje... Barcelona, 1882 (Memoria del Secretario del Jurado, D. Francisco Morera), p. 44.

21. Ibid., p. 44.

22. Ibid., id. 
La "cançó popular" Mirau mon cor de Joan Carreras fou interpretada tres vegades en el lapse de dos dies: en primer lloc, i amb caràcter d'estrena, el migdia del 26 de juny de 1881 al local oficial del Certamen, que era el pati del Seminari situat a la Rambla vella, convenientment adaptat per donar cabuda a 2.800 persones $^{23}$. En aquesta primera ocasió, presidida per l'Arquebisbe de Tarragona i amb assistència dels membres del jurat, l'interpretà la capella de música de la Catedral. ${ }^{24}$

A dos quarts de set de la tarda del mateix dia, el capítol de la seu tarragonina organitzà una "solemníssima funció religiosa" a la catedral, on, després de l'exposició del Santíssim i del cant del Trisagi, s'interpretà l'himne de Laudes (accèsit de J. Carreras) Summi Parentis Filio ${ }^{25}$ després de l'abrandat sermó del canonge vigatà Joan Collell ${ }^{26}$, tornà a interpretar-se, a càrrec de la capella de música de la catedral, el premiat Mirau mon cor de Joan Carreras.

El 27 de juny fou el Círculo Católico de Tarragona qui, volent regraciar els assistents als actes del dia anterior, volgué celebrar una vetllada literàrio-musical al mateix pati del Seminari on s'havia realitzat el repartiment dels premis del certamen el dia 26. La primera part de l'acte, que començà a les vuit del vespre, consistí en la recitació de diverses poesies catalanes (entre les quals, La barretina, de Verdaguer, premiada als Jocs Florals de Barcelona del 1880) i castellanes, i finí amb la interpretació de l'himne de Laudes de Joan Carreras a càrrec de "distinguidos profesores y cantantes"; a la segona part es llegiren obres de Garriga i Lliró, Victòria Peña d'Amer, Rubió i Collell, acabant amb el Mirau mon cor de Joan Carreras. ${ }^{27}$

$* * *$

La partitura de Jesús als pecadors («Mirau mon cor») de Joan Carreras, fou publicada, amb la de l'accèssit al mateix text de Damià Andreu, i l'Himne de Laudes Summi Parentis Filio, conjuntament amb els altres premis de caràcter literari, artístic, teològic i històric, en el volum editat a Barcelona el $1882 .^{28}$

23. L'arquitecte Ramon Salas dissenyà un quadrat de $30 \times 30 \mathrm{~m}$. en l'esmentat pati per a adaptar-lo a les necessitats del concurs. Aquell pati estava situat on avui hi ha la plaça Verdaguer. Vegeu altres detalls a la "Relación del Acto del Certamen y de las funciones celebradas en la ciudad de Tarragona los ías 2 y 27 de junio de 1881 ..." a Nacional Homenaje... Barcelona, 1882, p. 19-25.

24. Només s'interpretà aquesta obra: "El himno [de Laudes, accèsit de J. Carreras] y la otra canción [Mirau mon cor, accèsit de Damià Andreu] no se ejecutaron por la premura del tiempo". Cf. Id., ibid., p. 23.

25. “/.../Ejecutóse después por numeroso coro y nutrido [sic ] cuarteto de cuerda el Himno de Laudes..." Ibid., p. 23. L'apel-latiu de "nutrido" referit al quartet de corda cal entendre'l com a augment de cadascuna de les quatre veus del grup dels instruments de corda (violí I/II, viola, violoncel) que s'assenyalava a les bases del certamen. Tanmateix, si el cor era "numeroso", el reforç instrumental hi era adient.

26. El sermó s'havia encarregat al pare Fidel Fita, el qual no pogué assistir a l'acte; en segon lloc es pensà en el p. [Andreu] Martorell, que tampoc pogué predicar degut a la seva mala salut, i el mateix succeí amb l'Arquebisbe de Barcelona, José María de Urquinaona; finalment li encomanaren al canonge Collell, present a l'acte “...quien en catalán improvisó un discurso tan sentido y lleno de unción, entusiasmo y fuego, como todos los suyos, impresionando en gran manera á todos cuantos le escucharon". Ibid., p. 23.

27. Ibid., p. 24. A la fi de la primera part, i després de l’Himne de Laudes de Joan Carreras, la música (i.e., banda militar) del Regiment de Vizcaya executà “... con gran afinación una marcha de grandioso efecto y una fantasía sobre motivos de Roberto [Diavolo ].

28. Nacional homenaje... Barcelona, 1882. L’himne de Laudes Summi Parentis Filio a les p. 683-745; Jesús als Pecadors, de Joan Carreras, p. 749-756; id. de Damià Andreu, p. 757-763. Curiosament, Carreras dedica l'Himne de Laudes, 
Allò que les bases del premi número 20 establien, és a dir, una "composició musical de gènere popular", reeixí totalment a l'obra de Joan Carreras, que ha esdevingut viva des d'aleshores fins als nostres dies, especialment a les comarques tarragonines. La valoració dels mestres Felip Pedrell, Rafael Maneja i Ramon Bonet fou atinada no només en els termes del cànon de l'època, sinó àdhuc en el del seu esdevenidor, intuint que aquesta obra era quelcom més que el resultat d'un tràmit efímer o puntual.

La partitura publicada s'adiu estrictament amb les condicions del certamen, és a dir, un mínim de tres estrofes del poema a solo, duo, trio o cor, a criteri de l'autor, que "acompanyarà l'obra amb un senzill acompanyament o harmonizació per a instruments de teclat" (vegeu la nota 6).

A la secció de Música de la Biblioteca de Catalunya de Barcelona es conserven, a més, unes particel·les de la mateixa obra, que degueren de ser utilitzades per a la seva estrena, la interpretació de la qual anà a càrrec de la capella de música de la catedral. Es tracta del ms. M 1850/4, amb el següent títol: "Jesús als Pecadors / compost per Joan Carreras / Premiada al certámen / de / Tarragona (1881) / Basso". A l'angle superior esquerre, una marca en forma elíptica de segell de goma en tinta violeta, on es llegeix "Joan Carreras / Profesor de música"; a sota mateix, escrit en tinta negra, "Orquesta”. El títol és a la cara d'un bifoli apaisat que conté el Basso o Contrabaix; a dins hi ha set folis apaisats, escrits en tinta negra per l'anvers i el revers, corresponents a Flauta, Clarinete, Trompas en Mi I/II, Violín $1^{\circ}$ (dos exemplars de distinta mà), Violín $2^{\circ}$ i Violoncello; també hi ha dues quartilles rectes, escrites per una segona mà en tinta negra per l'anvers i el revers, corresponents al Cornetín i al Fiscorn.

Les tres interpretacions de l'obra, tot i mantenir la mateixa unitat vocal, pogueren posseir una distribució instrumental diferent; en tot cas, així sembla desprendre's dels papers conservats. La versió instrumental fou preparada segurament pel mateix compositor, atenent potser a la plantilla habitual de la capella de música de la catedral de Tarragona; efectivament, la major part de les obres que coneixem del mestre Rafael Maneja, servades a la seu tarragonina, són escrites per al següent elenc: Flauta, Clarinet, Trompa I/II, Trombó (intercanviable de vegades per un Fagot), Violí I/II, Violoncel i Contrabaix: el paral·lelisme és evident, fins i tot en la còpia d'un segon paper per al violí I (que permetia poder disposar de dos músics més per a un segon faristol d'aquest instrument), que concorda amb el "reforç" de la corda abans al·ludit.

Pel que fa als papers afegits de Cornetí i de Fiscorn (realment, es podia tocar l'obra sense aquests instruments, tot i que no diu ad libitum ni els configura com a ripieni), és possible que es copiessin sobre la marxa, i tal vegada, aprofitant que en el pati del Seminari, on tingué lloc l'estrena (migdia del 26 de juny) i la tercera interpretació de l'obra (vespre del 27), hi havia la banda de música militar del Regiment de Biscaia, de guarnició a Tarragona en aquell moment. El cas sembla més avinent encara per a la tercera interpretació, que no anà a càrrec de la capella de

en castellà, a l'Arquebsibe de Tarragona; sota el nom de l'autor, hi ha els apel·latius de "Caballero de la Real y Distinguida Orden de Carlos III" y "Organista de La Bisbal”. Quant a Jesús als pecadors, ambdós autors el titulen en català: Carreras el dedica a Joan B. Grau i Vallespinosa, Vicari General i futur bisbe d’Astorga. 
música de la catedral, sinó amb el concurs de "distinguidos profesores y cantantes", ja adduïts més amunt.

Entre aquesta versió instrumental i la publicada el $1882 \mathrm{amb}$ reducció per a instrument de tecla, hi ha petites variants, que afecten tant al nombre de compassos com algunes cèlllules de disseny formal.

Pel testimoni del Diario de Tarragona del 28 de juny de 1881 i del posterior La Veu de Montserrat del 9 de juliol del mateix any, podem assegurar que l'obra fou dirigida pel mateix autor, i que gaudí d'un bon acolliment des de la primera execució. ${ }^{29}$

Joan Carreras, que ja havia conegut Verdaguer en ocasió de les festes del mil·lenari de Montserrat de l'abril 1880, on resultà premiat amb un Ave Maris Stella ${ }^{30}$ continuà relacionant-se amb Verdaguer i amb Pedrell. Amb mossèn Cinto, perquè compongué més música amb la seva poesia, ${ }^{31} \mathrm{i}$ amb Pedrell, fonamentalment, per l'interès en la venda del seu fons de manuscrits $\mathrm{i}$ impresos musicals que constituïren el gruix del fons antic del que avui és la secció de Música de la Biblioteca de Catalunya. ${ }^{32}$

\section{Verdaguer, numen musical i classicus auctor de les lletres}

Seguint la mateixa línia del Nacional Homenaje de Tarragona del 1881, apareix un altre fet que lliga de diversa manera la relació entre Verdaguer i Pedrell. El organitzadors d'aquest certamen volgueren donar-hi la transcendència que el tema es mereixia; de fet fou el mateix Vicari General de l'arxidiòcesi, Joan B. Grau i Vallespinós, qui es posà en contacte amb Jacint Verdaguer, Fèlix Sardà i Salvany i Jaume Collell -artífexs de l'èxit recent de les festes de

29. El comentari de La Veu del Montserrat sembla referir-se només a la direcció de l'himne de Laudes, cantat per la capella de música de la catedral, la tarda del 26 de juny. També s'hi endevina una crítica encoberta al fet de no haver obtingut el premi, sinó l'accèssit: "Després la Capella de la matexa Catedral cantà l'himne premiat del Sr. Carreras, que ell mateix dirigí amb maestria, posant-se de relleu las bellesas d'exa obra musical, que no és la joya de menos vàlua que ha donat el certamen”. La Veu del Montserrat, Setmanari Popular de Catalunya. Vic, 9 de juliol de 1881. Núm. 27, p. 211 , col. b.

El Diario de Tarragona emperò, en la seva edició del 28 [26] de juny de 1881, recull la notícia de la direcció de l'autor: "La canción popular premiada la dirigió inmediatamente su autor, y fue desempeñada por músicos de la capilla de la Catedral, produciendo escelente efecto y y grangeándose el aplauso de toda la concurrencia. Ibid., p. 2, col. c.

30. Cf. La Veu del Montserrat, p. 211 , col. a: "\%.../ qui ja l'any passat en las festas del Milenar de Monserrat havia obtingut un merescut triunfo ab un magistral Ave Maris Stella..."

31. Una carta de Verdaguer a Carreras, datada a Barcelona el 24 de març de 1882, ens ho fa palès: "Caríssim amich y senyor meu: / Acabo de rebre los 12 exemplars de la / bellíssima composició ab que ha volgut / fer reviure y animar ma cansó de / las flors. Li agraesch en l'anima / l oferta que per si sola ya te per mi / un preu inestimable y li agraesch / també la inmerescuda dedicatoria. / Com aquestos dies han parlat y / parlan encara los diaris que V. m' / indica de varies obretes meves / si à V. no li sembla mal es- / peraré uns 8 dies d'enviarles / [dors] per que s'arriban á cansar de / veure y estampar sempre 1 mateix / nom. Me sembla que seia en be de / la obra. / Gracies mil repetesch, memories / als senyors Sitjar y à D. Rodolfo / Oliver. / Mane y dispose d'eix seu afm. / de [sic ] de cor l estima y li agraeix / l obsequi. / Jacinto Verdaguer Pbre". Biblioteca de Catalunya, fons Ramon Borràs.

32. Vegeu especialment M. C. Gómez-Elegido Ruizolalla: "La correspondencia entre Felipe Pedrell y Francisco Asenjo Barbieri" a Recerca Musicològica IV (1984), 205, 215-219, 232; i F. BonASTRE: "Documents epistolars de Barbieri adreçats a Felip Pedrell", Ibid., V (1985), 155-157. 
Mil·lenari de Montserrat- per tal de celebrar una reunió prèvia a Tarragona el primer d'octubre de $1880^{33}$, que servís per a traçar els grans trets del futur certamen.

L'interès de Verdaguer es manifesta no només en la seva voluntat d'ajudar a l'organització del certamen, sinó de prendre-hi part com a poeta, presentant-se com a candidat a un dels premis oferts, el número 14, que en les bases s'anunciava així:

“14. Un Colegio de señoritas con su Directora ofrece una «Rosa de plata ú oro, esmaltada», á la mejor Poesía catalana, dejando al arbitrio del poeta la elección del asunto, con tal que tenga relación con el Corazón de Jesus". ${ }^{34}$

L'esbós d'aquesta Poesia catalana l'anuncia en una carta al seu amic Jaume Collell, datada a Barcelona pels voltants del 8 de maig de 1881:

“... Per molts assumptos tinch de renunciar al plaher que tindria en assistir á vostra betllada, entre altres per desarrollar una idea d una poesia al Cor de Jesus, per presentar a Tarragona. La idea seria fer somiar á San Joan, sobre el pit del Salvador la nit de la Cena, la devoció futura y lo triunfo del Sagrat Cor. No he trobat encara la manera de tractar-ho; si a tu t vingués alguna idea sobre això, t'estimaré que m ajudes a completar la meva". ${ }^{35}$

Vers la tercera desena de maig, encara no la tenia enllestida ${ }^{36}$; en una altra carta posterior queda amb Jaume Collell per anar junts a Tarragona ${ }^{37} \mathrm{i}$, en vigílies del veredicte del certamen, confessa al seu amic Collell,

“/.../ Lo certamen de Tarragona s'acosta, i jo no hi vaig pas si tu no hi vens. No se si 1 Somni de S. Joan ha agradat ó no, mes 1 assumpto s em aixampla, com un cel que s esboyra. Tot sia en honor del Cor de Jesus". ${ }^{38}$

33. Epistolari de Jacint Verdaguer, Vol. III. Transcripció i notes per J. M. de Casacuberta i J. Torrent i Fàbregas. Ed. Barcino. Barcelona, 1971. Carta núm 228, de Joan B. Grau i Vallespinós a Verdaguer, datada a Tarragona, el 26 de setembre de 1880; pàgs. $54-56$.

34. Nacional Homenaje... Barcelona, 1882, p. 7. Una nota afegeix el nom de la Directora, "D. " María Alfonso". Aquest premi era el que deixava en major llibertat el poeta; d'altres premis literaris eren els núms. 9 (")/.../ Himno sobre el Corazón de Jesus triunfante, á proposito para ponerse en música, al estilo de una marcha grave y majestuosa "); 11 (")...। Composición poética castellana de Pío IX, Pontífice del Sagrado Corazón de Jesus "); 13 ("I.../ Oda heróica al Sagrado Corazón, enseña de combate y prenda de victoria para el pueblo cristiano en los tiempos presentes "); 15 (").../ Oda latina dedicada al Corazon de Jesus "); 16 (")... Oda al Corazon de Jesus, en catalan, valenciano ó mallorquin ");

35. Epistolari... Vol. III (1880-1882), Transcripció i notes per J. M. de Casacuberta i J. Torrent i Fàbregas. Ed. Barcino. Barcelona, 1971. Carta núm 254, p. 102-104. Els editors de l'Epistolari assenyalen en la nota 4 l'escassetat de temps amb que comptava Verdaguer per a enllestir el poema, atès que el termini finia, segons ells, el primer de juny. Realment, les bases de la convocatòria preceptuaven el 15 de maig com a termini ( $C f$. Nacional Homenaje... Barcelona, 1882, p. 7, primera de les Condiciones); però el Diario de Tarragona del 28 d'abril de 1881 notificava que "El plazo para la presentación de los trabajos espirará el $1^{\circ}$ de junio próximo". (Ibid., p. 2, col. c).

36. ".../ Mon Somni de San Joan, per ara te lluch de fer dormir als que 1 llegescan. Deu nos done inspiració y paciencia, que de tot se necessita per fer de poeta al dia d'abuy”. Cf. Epistolari..., vol. III. carta 256, dirigida a Jaume Collell. Ibid., p. 110-112.

37. Carta de Verdaguer a Collell, vers el 10 o 11 de juny: “/.../ T espero per anar á Tarragona lo dia dels premis, ó de las carabassas, que una cosa y altre m'es igual quan se tracta d un certamen dedicat al Cor de Jesus. Ibid., p. 118.

38. Ibid., p. 121 . 
El Somni de Sant Joan obtingué el premi desitjat, i el desvetllament de la seva autoria provocà grans aplaudiments del públic que festejà la presència de l'insigne poeta i el seu triomf ${ }^{39}$; tanmateix, l'obra meresqué els honors d'ésser recitada en continent, en aquest cas, pel seu amic el canonge Collell, atent a totes les necessitats del certamen; degut a la migradesa del temps del què es disposava, només foren recitades públicament les següents obres: l'himne català del guanyador del premi núm. 9 (Nemesi Fons); l’oda castellana del guanyador del premi núm. 13 (Josep Peris i Pascual) i l'accèsit del mateix premi, Enrique García Bravo; Lo Somni de sant Joan de Verdaguer i l'oda sàfica catalana del guanyador del premi núm. 16 (Francesc de Paula Ribas i Servet, pvre.). També, en aquest acte de proclamació dels guanyadors, fou interpretada per primera vegada l'obra verdagueriana Jesús als pecadors del premiat Joan Carreras, com s'ha dit més amunt. ${ }^{40}$

El premi atorgat a Verdaguer constituí el millor testimoni de la vàlua del certamen de Tarragona: però també hi hagueren altres guardonats - ultra els dos compositors ja esmentats- que col·laboraren a aixecar el nivell de qualitat d'aquest Homenatge Nacional; citem, entre ells, Josep Torres i Bages, en aquell moment "prevere de Barcelona", que guanyà el premi núm. 7, dedicat al millor escrit sobre "la influencia social que la devocion al Sagrado Corazon está destinada á ejercer en los tiempos modernos" ${ }^{41}$; el pintor i dibuixant Dionís Baixeras, que obtingué l'àccèssit al premi núm. 17, ofert a la millor "pintura original del Corazon de Jesus"42. Tanmateix, cal esmentar al grau d'exigència del jurat, la qual cosa garantia el prestigi del certamen: dels 21 premis convocats, 7 foren reconvertits en accèssits i 2 es declararen deserts. ${ }^{43}$

\section{Pedrell, compositor verdaguerià}

El nucli del concepte pedrellià sobre l'escola nacionalista musical fou exposat amb claredat a Por nuestra música..., publicat el setembre de 1891 amb motiu de la composició de la Tri-

39. “.../ Una salva nutridísima de aplausos, que se repetía al aparecer el premiado, respondía á cada nombre, recibiendo una verdadera ovación los señores D. Andrés Martorell, sacerdote de la Compañía de Jesús, el laureado D. Jacinto Verdaguer y los Dres. Llobet y Nuet, catedráticos del Seminario.” Cf. Nacional Homenaje... Barcelona, 1882, p. 21 ("Relación del acto del certamen...")

40. Ibid., p. 21-23.

41. Ibid., p. 6 (Bases del certamen), 22 (identifcació dels guanyadors) i 41 (Memòria del Secretari: "Un talento superior desarrolla en la produccion que ha venido al concurso bajo el $\mathrm{n}^{\circ} 44$ el tema sobre Influencia social /.../ La profundidad de la doctrina, lo vasto del plan, la magnificencia con que está tratado el asunto y otras cualidades importantes hacen de esta obra una preciosísima joya que el Jurado, altamente satisfecho, recompensa con el premio"). També s'hi afegiren dos accèssits, que correspongueren a Francesc Pagès, de Barcelona, i a Francesc de Paula Ribas i Servet, prevere i catedràtic del Seminari de Tarragona.

42. El premi no fou adjudicat, i en el seu lloc s'oferiren dos accèssits, a Ramon Sarrió i Paya de València i Dionís Baixeras [de Barcelona]. Ibid., p. 22 i 43. p. 42 i 44 .

43. Foren passats a accèssit els premis núm. 2, 4, 5, 11, 17, 18 i 19; no s'adjudicaren el premis núm. 10 i 21 . Ibid., 
logia Els Pirineus, segons poema de Víctor Balaguer. ${ }^{44}$ Allí, el compositor preceptuava la base del "cant nacional", el cant del poble, com a imprescindible per a bastir una escola musical amb veu pròpia dins el panorama cultural de la música europea del seu temps. Aquest cant posseïa dues etapes: la primera es creia de creació popular, seguint la teoria herderiana del Volkgeist, i la segona era la que ell anomenava la "música d'autor", que li prestava el treball personificat, la dialèctica artística i qualificació estilística i històrica. Aquests materials s'havien de fondre amb la música coetània, per tal d'universalitzar-ne el resultat, tot i donant un equilibri entre la veu pròpia i la internacional. ${ }^{45}$ Aquesta idea fructificaria en els seus deixebles, i especialment, en Lluís Millet i l'Orfeó Català, que esdevingué el ressò de la música enmirallada en l'obra poètica de Verdaguer.

Com he escrit més amunt, Pedrell musicà a principis de 1880 , mentre era a París, diverses estrofes de Jesús als Pecadors de Verdaguer, publicat uns mesos enrere. En aquesta obra, empra el poema verdaguerià com a text inspirador, al que hi atorga un caràcter dramàtic amb la seva música; no hi ha l'accent, ni molt menys encara, la citació de cap melodia popular. Altrament, és una composició que conserva en el seu catàleg, salvant-la de la destrucció que afectà a moltes altres de la seva joventut. ${ }^{46}$

Per cert, el manifest Por nuestra música va dedicat al Marquès de Comillas, al qual servia com a capellà Mn. Jacint Verdaguer; no sabem si Pedrell demanà directament l'ajut d'aquest darrer per a que l'ajudés en la representacció d'Els Pirineus, o ho feu, pel que sembla, a través del P. Eduardo Llanes. ${ }^{47}$

Mentrestant, la terrible crisi personal del poeta augmenta la pregonesa de la seva obra, que acreix encara més a ran de la seva mort, el juny de 1902; poc temps més enllà, Pedrell esgota a poc a poc el seu entusiasme de la vida madrilenya, i retorna, a finals de 1904, a Barcelona; el seu bagatge espiritual consisteix en un recull de composicions musicals amb text de Verdaguer. $^{48}$

L'índex d'aquestes obres comprèn set altres poesies musicades de mossèn Cinto, amb expressió de la data de la seva publicació i del nombre de planxes que ocupava cada composició: ${ }^{49}$

44. Pedrell, F.: Por nuestra música. Algunas observaciones sobre la magna cuestión de una Escuela Lírico Nacional, motivadas por la Trilogía (Tres cuadros y un prólogo) Los Pirineos, poema de D. Víctor Balaguer, música del que suscribe, y expuestas por... Barcelona, Henrich y $\mathrm{C}^{\mathrm{a}}, 1891$.

45. Id., Ibid., p. 36-41.

46. Pedrell, F.: Catàleg autògraf de les seves obres: "/.../ Poco antes de trasladar mi domicilio á Madrid, he hecho un auto de fe destruyendo sin pena, todas las composiciones que no merecían conservarse. Van señaladas con lápiz encarnado todas las que destruí". Ms. M. 1970 de la B. C. de Barcelona, f. 46, datat a finals d'octubre de 1894.

47. Cortès, F.: El Nacionalisme Musical de Felip Pedrell a través de les seves òperes: Els Pirineus, La Celestina i El Comte Arnau. Tesi Doctoral, dirigida per F. Bonastre. UAB, 1994. Vol. I bis, p. 251 i ss.

48. Pedrell, F.: Catàleg autògraf de les seves obres: “/.../ Durante trimestre Septiembre, Nov. y Dic. produzco casi todas las obras (vide más adelante sección A y B) del Salterio Sacro-Hispano, segunda època. Enfermo en Madrid, de cuidado. Por consejo de los médicos me traslado á Barcelona, dónde llegamos 24 de diciembre" F. 54v, corresponent al final de 1904.

49. Id., Ibid., f. 263-263v.

Anuario Musical, 57 (2002) 
Títol

Sospirs

Les Cinch roses

Lo Cor de Jesús

Sant Joseph

L'herba de l'amor

Lo Sant nom de Jesús (C. místich de Nadal)

La Sagrada Família
Data

(Tonada de Cantiga d'Alfons X)

(Idili místich)

(Cant místich)

(Cant místich)

(Cant sacre)
Nombre de planxes

Set.-Nov. 1904

Id. 6

Des. 1904

Gen. 1905

Feb. 1905

[Id.] 14

Feb. $1905 \quad 6^{50}$

El tractament musical d'aquest repertori és molt més diversificat, i segueix la senzillesa de la melodia popular, amb l'ús de les modalitats escalístiques i la polirítmia pròpia de la música catalana tradicional; tanmateix, agermanada amb el cant gregorià, del qual s'inicià altra vegada un pregon retrobament.

La llarga mà de Pedrell homenatja Verdaguer amb un altre dels seus deixebles, Manuel de Falla, a través del seu amic i marmessor, Joan Gisbert, que li'n feu a mans un exemplar de l'Atlàntida, amb el desig que li posés música. I, per damunt de tot, el llegat pedrellià és presidit pel deler per la troballa d'una música pròpia, treballat especialment damunt l'impresssionant speculum de l'obra poètica verdagueriana; ambdós personatges atorgaren al nostre país un testimoni indicador que crearen, desenvoluparen i ensenyaren amb el seu exemple.

50. Inicialment a 1 veu i orgue, al f. 55 del ms. citat es llegeix: "/... La Sagrada Família, arreglo per a [4] veus mixtes escrit per a l'Orfeó Català, estrenat el 19 Novembre". 